\title{
MART-I0, a newly synthesized vitamin D analog, represses metastatic potential of head and neck squamous carcinoma cells
}

This article was published in the following Dove Press journal:

Drug Design, Development and Therapy

17 June 2016

Number of times this article has been viewed

\author{
Shih-Wei Yangl,* \\ Chi-Ying Tsai ${ }^{2, *}$ \\ Yi-Chun Pan ${ }^{3}$ \\ Chun-Nan Yeh ${ }^{4}$ \\ Jong-Hwei S Pang 5 \\ Masashi Takano6 \\ Atsushi Kittaka ${ }^{6}$ \\ Horng-Heng Juang7 \\ Tai C Chen ${ }^{8}$ \\ Kun-Chun Chiang ${ }^{4,9}$ \\ 'Department of Otolaryngology - \\ Head and Neck Surgery, Chang \\ Gung Memorial Hospital, Keelung, \\ ${ }^{2}$ Department of Oral and Maxillofacial \\ Surgery, Chang Gung Memorial \\ Hospital, Taoyuan, ${ }^{3}$ Department of \\ General Dentistry, Chang Gung \\ Memorial Hospital, Chang Gung \\ University, Keelung, ${ }^{4}$ General Surgery \\ Department, Chang Gung Memorial \\ Hospital, Keelung, ${ }^{5} \mathrm{Graduate}$ Institute \\ of Clinical Medical Sciences, College \\ of Medicine, Chang Gung University, \\ Taoyuan, Taiwan, Republic of China; \\ ${ }^{6}$ Faculty of Pharmaceutical Sciences, \\ Teikyo University, Tokyo, Japan; \\ ${ }^{7}$ Department of Anatomy, College \\ of Medicine, Chang Gung University, \\ Taoyuan, Taiwan, Republic of China; \\ ${ }^{8}$ Endocrine Core Laboratory, Boston \\ University School of Medicine, Boston, \\ MA, USA; ${ }^{9} Z$ ebrafish Center, Chang \\ Gung Memorial Hospital, Keelung, \\ Taiwan, Republic of China \\ *These authors contributed equally \\ to this work
}

Correspondence: Kun-Chun Chiang General Surgery Department, Chang Gung Memorial Hospital, Chang Gung University, 222 Mai-Chin Road, Keelung 204, Taiwan, Republic of China

Email robertviolet6292@yahoo.com.tw

\begin{abstract}
Even with multidisciplinary treatment, the prognosis and quality of life of patients diagnosed with head and neck squamous cell carcinoma (HNSCC) are still not satisfactory. Previously, 19-Nor-2 $\alpha$-(3-hydroxypropyl)- $1 \alpha, 25(\mathrm{OH})_{2} \mathrm{D}_{3}$ (MART-10), the new brand $1 \alpha, 25(\mathrm{OH})_{2} \mathrm{D}_{3}$ analog, has been demonstrated to be an effective drug to inhibit HNSCC growth in vitro. Since most cancer patients die of metastasis, in this study, the antimetastatic effect of MART-10 on HNSCC was investigated. Our results reveal that both $1 \alpha, 25(\mathrm{OH})_{2} \mathrm{D}_{3}$ and MART-10 effectively repressed the migration and invasion of HNSCC cells, with MART-10 being much more potent than $1 \alpha, 25(\mathrm{OH})_{2} \mathrm{D}_{3}$. The antimetastatic effect of $1 \alpha, 25(\mathrm{OH})_{2} \mathrm{D}_{3}$ and MART-10 was mediated by attenuation of epithelial-mesenchymal transition (EMT), which was supported by the finding that the expression of EMT-inducing transcriptional factors, Sail and Twist, was inhibited by $1 \alpha, 25(\mathrm{OH})_{2} \mathrm{D}_{3}$ and MART-10. The upregulation of E-cadherin and downregulation of $\mathrm{N}$-cadherin in FaDu cells induced by both drugs further confirmed the repression of EMT. In addition, $1 \alpha, 25(\mathrm{OH})_{2} \mathrm{D}_{3}$ and MART-10 treatment inhibited intracellular MMP-9 expression and extracellular MMP activity in FaDu cells. Collectively, our results suggest that the lesscalcemia $1 \alpha, 25(\mathrm{OH})_{2} \mathrm{D}_{3}$ analog, MART-10, is a promising drug for HNSCC treatment. Further clinical studies are warranted.
\end{abstract}

Keywords: EMT, head and neck cancer, vitamin D analog, metastasis, MART-10

\section{Introduction}

Head and neck squamous cell carcinoma (HNSCC), with 500,000 newly diagnosed cases yearly, ${ }^{1}$ is a challenge for clinicians since radical surgery is the cornerstone treatment for HNSCC; however, the complex anatomy of the head and neck complicates surgical treatment. Traditional radiotherapy may sometimes be applied in HNSCC patients, but this kind of treatment may further worsen their quality of life. Even with multidisciplinary treatment, most HNSCC patients finally die of cancer metastasis. Currently, survival rates of $61 \%$ and $50 \%$ are observed for HNSCC patients at 5 years and 10 years, respectively. ${ }^{2}$ Thus, development of a new regimen to prevent HNSCC metastasis should be prioritized to improve the survival.

Since the hormone-like role of vitamin D has been discovered, a variety of nonmineral functions of vitamin $\mathrm{D}$ have been demonstrated. $1 \alpha, 25(\mathrm{OH})_{2} \mathrm{D}_{3}$, the active form of vitamin $\mathrm{D}$, has been widely studied in anticancer research category due to the prodifferentiation, proapoptosis, antiangiogenesis, and antiproliferation effects of $1 \alpha, 25(\mathrm{OH})_{2} \mathrm{D}_{3}$ noted in the past decades. ${ }^{3,4}$ To exert its hormone-like functions, $1 \alpha, 25(\mathrm{OH})_{2} \mathrm{D}_{3}$ needs to bind with vitamin $\mathrm{D}$ receptor (VDR), which has been shown to exist in a variety of tissues in humans, indicating that $1 \alpha, 25(\mathrm{OH})_{2} \mathrm{D}_{3}$ is able to affect 
almost all human tissues. However, hypercalcemia, which is induced by high dose of $1 \alpha, 25(\mathrm{OH})_{2} \mathrm{D}_{3}$, impedes the clinical application of vitamin $\mathrm{D}$ for cancer treatment. For this reason, numerous vitamin D analogs have been synthesized with the aim to minimize hypercalcemia-inducing characteristics and to maximize the anticancer effect. $1 \alpha, 25(\mathrm{OH})_{2} \mathrm{D}_{3}$ has been shown to be able to repress HNSCC cell growth, mainly through cell cycle arrest in G0/G1 phase. ${ }^{5,6}$ EB1089, a kind of $1 \alpha, 25(\mathrm{OH})_{2} \mathrm{D}_{3}$ analog, was demonstrated to inhibit HNSCC cell growth in vitro and in vivo. ${ }^{7}$ However, limited studies are available regarding the application of $1 \alpha, 25(\mathrm{OH})_{2} \mathrm{D}_{3}$ and its analogs in HNSCC metastasis.

$19-$ Nor- $2 \alpha-(3$-hydroxypropy 1$)-1 \alpha, 25(\mathrm{OH})_{2} \mathrm{D}_{3}$ (MART-10) is a newly synthesized vitamin D analog, ${ }^{8}$ which has been proved to have three times VDR-binding affinity than $1 \alpha, 25(\mathrm{OH})_{2} \mathrm{D}_{3}{ }^{9,10}$ and much more resistance to CYP24A-mediated degradation, ${ }^{11}$ suggesting that MART-10 is a potential vitamin D analog for cancer treatment. So far, our group has demonstrated that MART-10 exerts more potent anticancer growth effect than $1 \alpha, 25(\mathrm{OH})_{2} \mathrm{D}_{3}$ in a number of cancers ${ }^{12-14}$ and is active in vivo without inducing hypercalcemia. ${ }^{15}$ MART-10 has further been demonstrated to attenuate the metastatic potential of anaplastic thyroid cancer, breast cancer, and pancreatic cancer. ${ }^{16-18}$ We have previously shown that MART-10 could effectively repress cancer cell growth in HNSCC. ${ }^{19}$ Since metastasis is the main cause of poor prognosis of HNSCC, in this study, we aimed to investigate the effect of MART-10 on HNSCC metastatic potential to further justify the clinical application of MART-10 for HNSCC treatment.

\section{Materials and methods Vitamin D compounds}

$1 \alpha, 25(\mathrm{OH})_{2} \mathrm{D}_{3}$ was purchased from Sigma-Aldrich (St Louis, MO, USA). MART-10 was synthesized according to Kittaka et $\mathrm{al}^{8}$ as described previously.

\section{Cell culture}

FaDu and SCC-25 cells, human SCC cell lines, were purchased from Bioresource Collection and Research Center (Taoyuan, Taiwan). Cells were grown in accordance with the guidance. Culture medium was changed three times per week. The authors advise that in Taiwan, no institutional review board approval is needed for cell culture studies.

\section{Trans-well filter migration assay}

FaDu or SCC-25 cells were pretreated for 2 days with indicated concentrations of either MART-10 or $1 \alpha, 25(\mathrm{OH})_{2} \mathrm{D}_{3}$. Cells were then seeded on each trans-well filter with $8.0-\mu \mathrm{m}$ pores (CoStar, Cambridge, MA, USA). The detailed procedure was as previously described. ${ }^{16}$ Migrating cells were stained with Liu's stain and washed with $1 \times$ PBS twice and counted under four random high-power microscopic fields $(100 \times)$ per filter. The experiments were performed in triplicates.

\section{Matrigel invasion assay}

FaDu or SCC-25 cells were pretreated with indicated concentrations of $1 \alpha, 25(\mathrm{OH})_{2} \mathrm{D}_{3}$ or MART-10. The assay was performed as previously described. ${ }^{16}$ The invading cells were fixed by $4 \%$ paraformaldehyde $(0.4 \% \mathrm{NaOH}, 4 \%$ paraformaldehyde, and $3.8 \%$ hydrated sodium borate, $\mathrm{pH} 9.5$ ). The invading cells were digitally photographed and counted under the microscope (IX71; Olympus Corporation, Tokyo, Japan). Experiments were performed in triplicates and repeated at least three times.

\section{Gelatin zymography}

After 2 days of indicated $1 \alpha, 25(\mathrm{OH})_{2} \mathrm{D}_{3}$ or MART-10 treatment, the conditioned media were run under nonreducing conditions in $10 \%$ sodium dodecyl sulfate-polyacrylamide gels containing $2 \mathrm{mg} / \mathrm{mL}$ gelatin (Chemicon International Inc., Temecula, CA, USA). The detailed procedures were as described previously. ${ }^{16}$

\section{Western blot}

The detailed procedures for Western blot were described previously. ${ }^{16}$ The antibodies used in this experiment were monoclonal antibodies against E-cadherin (1:1,000,\#3195; Cell Signaling Technology, Irvine, CA, USA), N-cadherin (1:1,000, \#13116; Cell Signaling Technology), Snail (1:1,000, \#3879; Cell Signaling Technology), Slug (1:1,000, \#9585; Cell Signaling Technology), Twist (1:400, ab49254; Abcam, Cambridge, UK), MMP-2 (1:1,000,\#13132; Cell Signaling Technology), and MMP-9 (1:1,000,\#13667; Cell Signaling Technology). The blots were detected with enhanced chemiluminescence reagents (WBKLS0500; EMD Millipore, Billerica, MA, USA). Membranes were detected with VersaDoc ${ }^{\text {TM }}$ Imaging System (Bio-Rad Laboratories Inc., Hercules, CA, USA).

\section{Statistics method}

The data from each group were compared by Student's $t$-test. $P$-value $<0.05$ was considered as a significant difference. The program of Excel 2010 was used to perform the statistics.

\section{Result}

Evaluation of $\mathrm{I} \alpha, 25(\mathrm{OH})_{2} \mathrm{D}_{3}$ and MART- 10 effects on HNSCC cell metastasis

To investigate the effects of $1 \alpha, 25(\mathrm{OH})_{2} \mathrm{D}_{3}$ and MART-10 on the metastatic potential of HNSCC cells, invasion and 
migration assays were conducted. As shown in Figure 1A, $10^{-8} \mathrm{M}$ or $10^{-7} \mathrm{M} 1 \alpha, 25(\mathrm{OH})_{2} \mathrm{D}_{3}$ repressed $\mathrm{FaDu}$ cell migration to $92 \% \pm 4 \%$ or $46 \% \pm 3 \%$ of the control. MART- 10 , at $10^{-8} \mathrm{M}$ and $10^{-7} \mathrm{M}$, decreased $\mathrm{FaDu}$ cells migration to $53 \% \pm 3 \%$ and $31 \% \pm 5 \%$ of the control. For FaDu cell invasion (Figure 1B), $90 \% \pm 5 \%$ and $43 \% \pm 4 \%$ invasions of the control were observed when treated by $10^{-8} \mathrm{M}$ and $10^{-7} \mathrm{M} 1 \alpha, 25(\mathrm{OH})_{2} \mathrm{D}_{3} ; 10^{-8} \mathrm{M}$ and $10^{-7} \mathrm{M}$ MART-10 inhibited FaDu cell invasion to $52 \% \pm 4 \%$ and $30 \% \pm 3 \%$ of the control. Our result indicates that both $1 \alpha, 25(\mathrm{OH})_{2} \mathrm{D}_{3}$ and MART-10 could effectively repress $\mathrm{FaDu}$ cell metastasis, with MART-10 being much more potent than $1 \alpha, 25(\mathrm{OH})_{2} \mathrm{D}_{3}$. Figure 2 shows that the invasion and migration of SCC- 25 cells were attenuated by $1 \alpha, 25(\mathrm{OH})_{2} \mathrm{D}_{3}$ and MART-10 in a dose-dependent manner, with MART-10 having stronger effect, in line with the finding shown in Figure 1.

\section{Evaluation of effects of $\mathrm{I} \alpha, 25(\mathrm{OH})_{2} \mathrm{D}_{3}$ and MART-I0 on expression of epithelial-mesenchymal transition-related transcriptional factors, Snail, Slug, and Twist, in Fadu cells}

Since epithelial-mesenchymal transition (EMT) is a vital process for cancer metastasis, we evaluated the effects of $1 \alpha, 25(\mathrm{OH})_{2} \mathrm{D}_{3}$ and MART-10 on EMT-inducing transcriptional factors in $\mathrm{FaDu}$ cells. Figure 3 demonstrates that $10^{-7} \mathrm{M} 1 \alpha, 25(\mathrm{OH})_{2} \mathrm{D}_{3}$ induced a decrease of Snail and Twist expressions to $0.81 \pm 0.09$ and $0.78 \pm 0.08$ folds of the control, without significant impact on Slug expression in FaDu cells. A similar result was observed when treated by MART-10.

\section{Evaluation of E-cadherin and $\mathrm{N}$-cadherin expressions in $\mathrm{FaDu}$ cells after $\mathrm{I} \alpha, 25(\mathrm{OH})_{2} \mathrm{D}_{3}$ or MART-I 0 treatment}

To further understand the mechanisms whereby $1 \alpha, 25(\mathrm{OH})_{2} \mathrm{D}_{3}$ and MART-10 inhibited HNSCC metastasis, E-cadherin and $\mathrm{N}$-cadherin expressions of $\mathrm{FaDu}$ cells were measured by Western blot after 2 days of $1 \alpha, 25(\mathrm{OH})_{2} \mathrm{D}_{3}$ or MART-10 treatment. As shown in Figure $4,10^{-7} \mathrm{M} 1 \alpha, 25(\mathrm{OH})_{2} \mathrm{D}_{3}$ or MART-10 increased E-cadherin expression of FaDu cells to $1.3 \pm 0.11$ or $1.52 \pm 0.08$ fold. $\mathrm{N}$-cadherin expression was repressed by $10^{-8} \mathrm{M} 1 \alpha, 25(\mathrm{OH})_{2} \mathrm{D}_{3}$ or MART-10.

\section{Evaluation of effects of $I \alpha, 25(\mathrm{OH})_{2} \mathrm{D}_{3}$ and MART-I 0 on intra- and extracellular MMP-2 and MMP-9 expressions in $\mathrm{FaDu}$ cells}

Since MMP-2 and MMP-9 function as two important proteins to digest extracellular matrix to facilitate cell invasion, the intracellular and extracellular MMP-2 and MMP-9 were thus evaluated. Figure 5A and B shows that the intracellular MMP-9 expression, but not MMP-2, in FaDu cells was repressed by both $1 \alpha, 25(\mathrm{OH})_{2} \mathrm{D}_{3}$ and MART-10 at the concentration of $10^{-7} \mathrm{M}$. The extracellular MMP-2 and MMP-9 activities were measured by zymography assay. Figure 5C reveals that the extracellular MMP-9 activity was attenuated in FaDu cells as treated $1 \alpha, 25(\mathrm{OH})_{2} \mathrm{D}_{3}$ or MART-10.

\section{Discussion}

The higher potency of MART-10 than $1 \alpha, 25(\mathrm{OH})_{2} \mathrm{D}_{3}$ could be mainly attributed to two reasons. The first is that MART-10 is a poor substrate to CYP24A1, the main enzyme to catabolize $1 \alpha, 25(\mathrm{OH})_{2} \mathrm{D}_{3}$ in humans, in a cell-free reconstituted system, ${ }^{20}$ which is also supported by a docking analysis showing that 24 hydroxylation of MART-10 is not as easy as that of $1 \alpha, 25(\mathrm{OH})_{2} \mathrm{D}_{3} \cdot{ }^{21}$ The higher resistance to CYP24A1 degradation indicates that MART-10 could act longer. The second is the higher VDR-binding affinity of MART-10 than $1 \alpha, 25(\mathrm{OH})_{2} \mathrm{D}_{3}$, which was confirmed by the X-ray crystallographic structure of MART-10 complex bound with VDR. ${ }^{9}$ Since most $1 \alpha, 25(\mathrm{OH})_{2} \mathrm{D}_{3}$-mediated genomic functions are VDR dependent, the higher VDR-binding affinity of MART-10 reasonably induces higher VDR transactivation. Collectively, MART is expected to have a much more potent effect than $1 \alpha, 25(\mathrm{OH})_{2} \mathrm{D}_{3}$.

In this study, we showed that the newly synthesized $1 \alpha, 25(\mathrm{OH})_{2} \mathrm{D}_{3}$ analog, MART-10, exhibited more potent effect than $1 \alpha, 25(\mathrm{OH})_{2} \mathrm{D}_{3}$ on attenuation of HNSCC metastatic potential through EMT repression, which was implemented by reversing cadherin switch (upregulation of E-cadherin and downregulation of N-cadherin), inhibition of Snail, Twist, and MMP-9. Given that MART-10 has already been proved to effectively repress HNSCC cell growth, ${ }^{19}$ MART-10 should be deemed as a promising drug for HNSCC treatment.

Cancer metastasis is the cause of cancer-related death. The first step of cancer metastasis is tumor cell dissemination, which is triggered by a decrease in cell-cell adhesion and an increase in cell motility and invasiveness, thus enabling tumor cells to detach from the primary lesions, invade through the surrounding matrix, and migrate to other sites. ${ }^{22}$ To achieve this, epithelial cancer cells need to go through one process to become invasive, which is EMT. EMT is a process during which epithelial cells transform into mesenchymal-like cells and is important for the development of normal tissues. ${ }^{23}$ However, EMT could be reactivated by cancer cells to obtain motility and become invasive. ${ }^{24}$ In addition, EMT is able to render tumor cells more resistant to chemotherapies ${ }^{25,26}$ and 

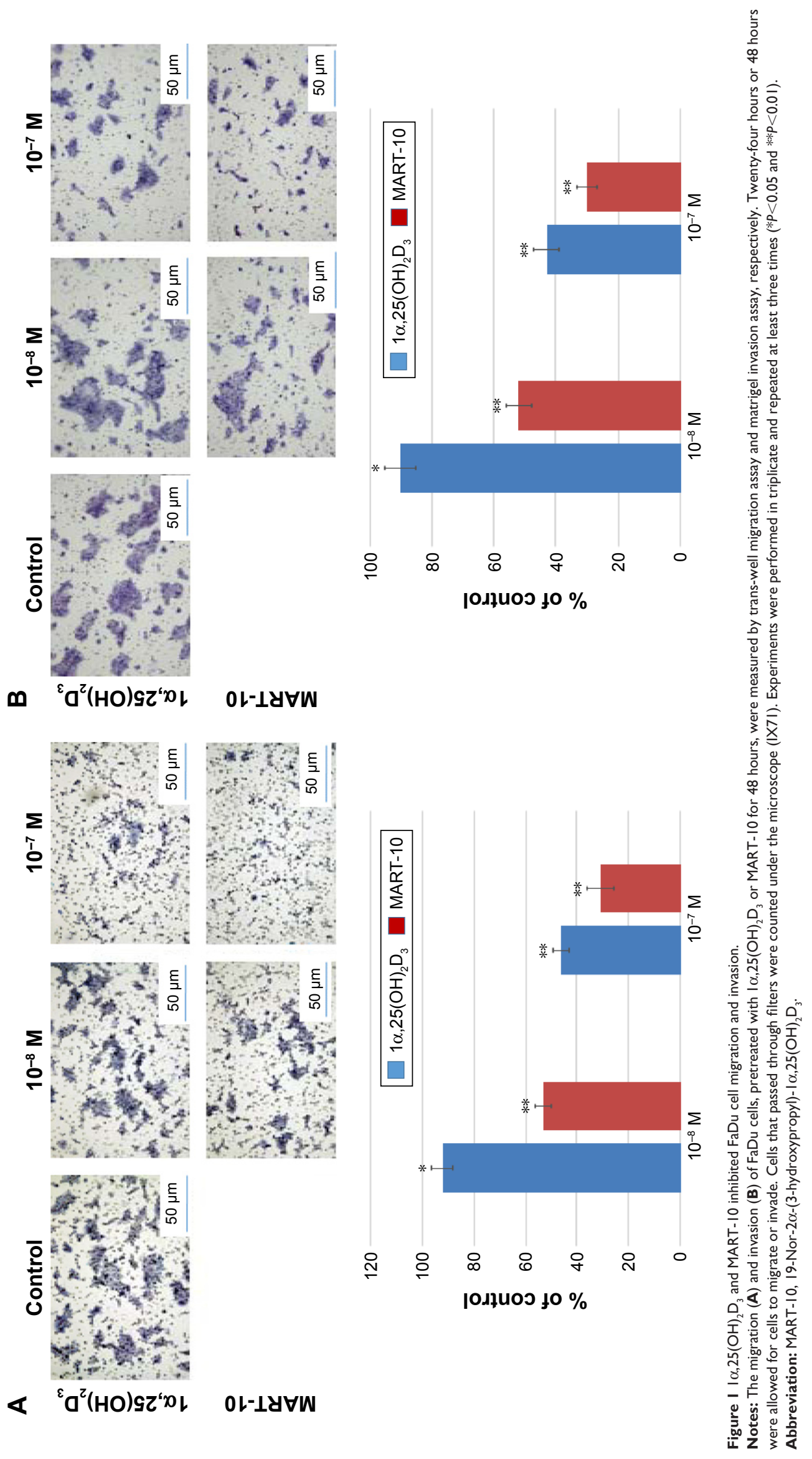

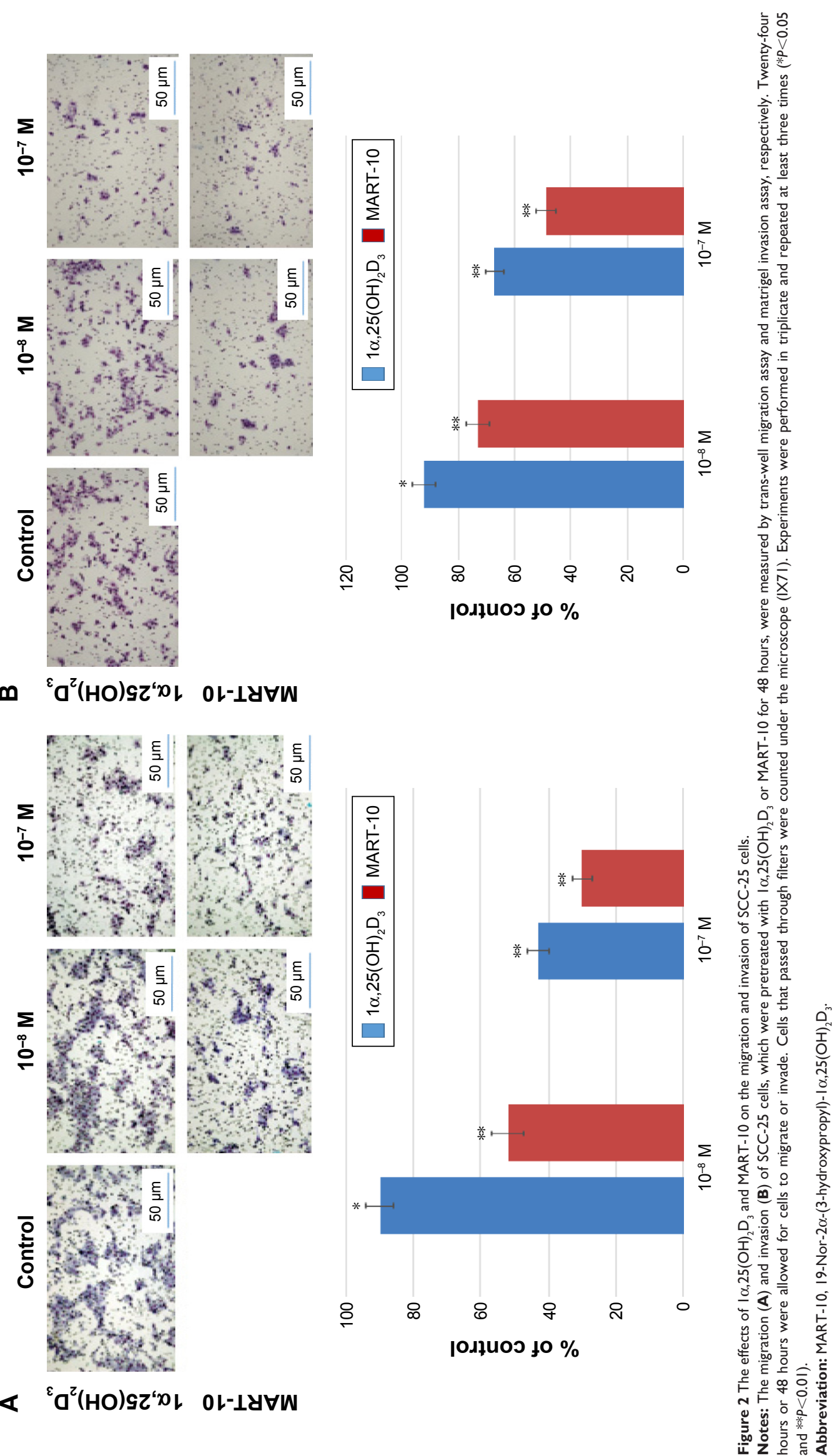

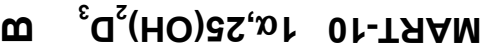
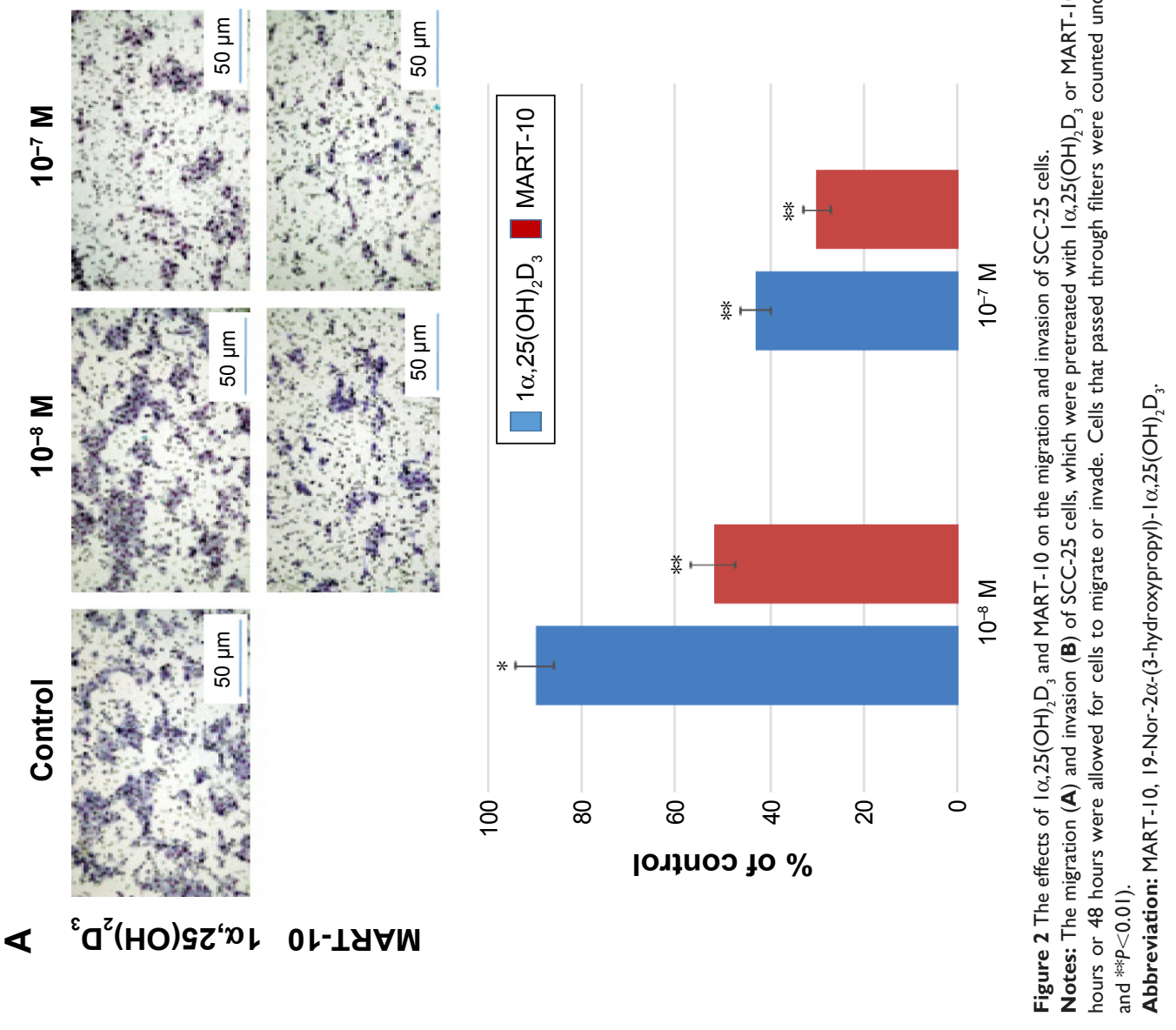

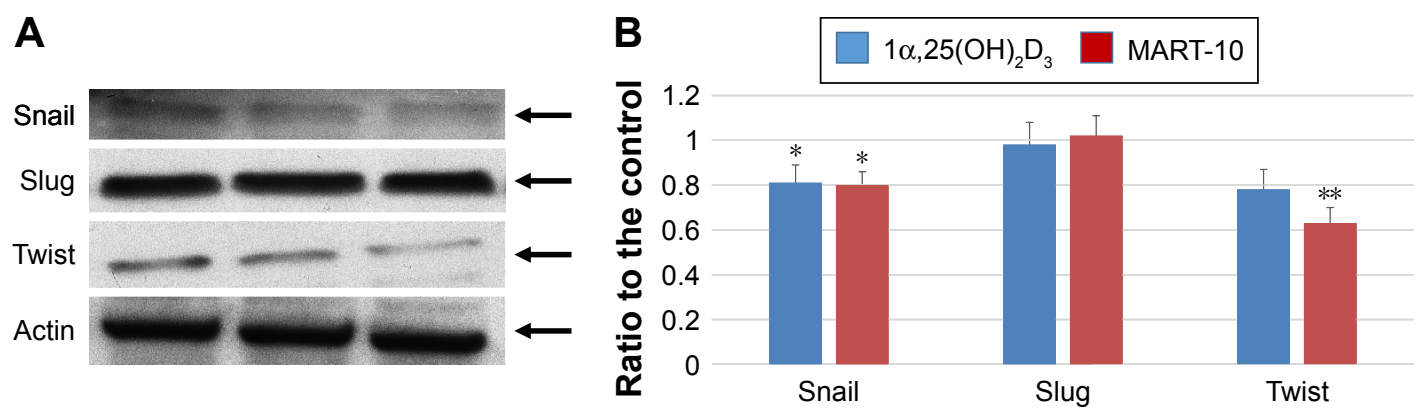

Figure 3 Effects of $\mathrm{I} \alpha, 25(\mathrm{OH})_{2} \mathrm{D}_{3}$ or MART-IO on the expressions of Snail, Slug, and Twist, in FaDu cells.

Notes: (A) Western blot showing the expressions of Snail, Slug, and Twist in FaDu cells after 2 days of $10^{-7} M I \alpha, 25(O H) D_{2} D_{3}$ or MART-I0 treatment. Tubulin was used as the loading control. (B) Quantitative result of Snail, Slug, and Twist expressions in FaDu cells with or without treatment. Each value is a mean \pm SD of three independent determinations $(* P<0.05$ and $* * P<0.01)$

Abbreviation: MART-I0, I9-Nor-2 $\alpha-\left(3\right.$-hydroxypropyl)- $\mid \alpha, 25(\mathrm{OH})_{2} \mathrm{D}_{3}$.

A

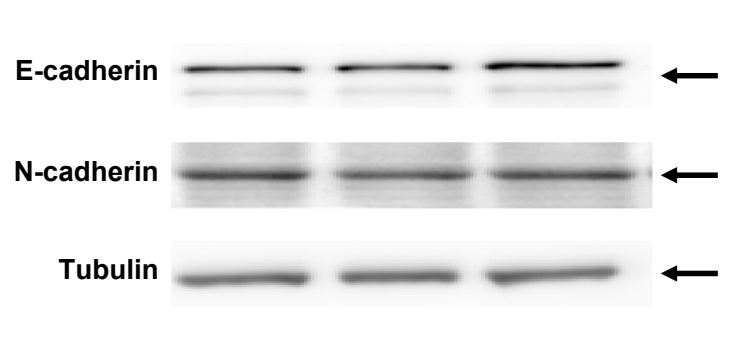

B

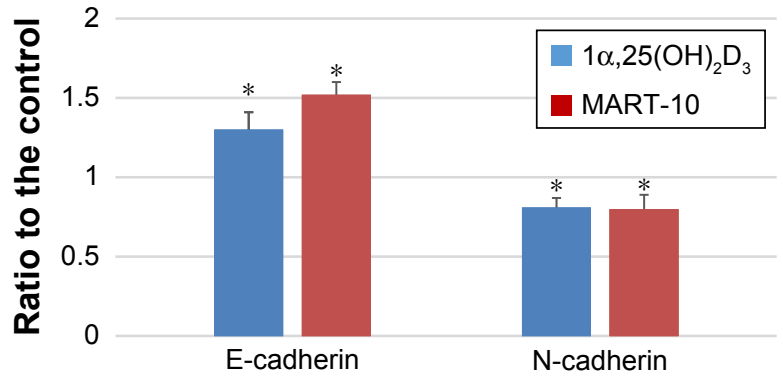

Figure $4 \mathrm{I} \alpha, 25(\mathrm{OH})_{2} \mathrm{D}_{3}$ or MART-I0 induced an increase in E-cadherin but a decrease in $\mathrm{N}$-cadherin expression in FaDu cells.

Notes: (A) Western blot depicting the expressions of E-cadherin and $\mathrm{N}$-cadherin in FaDu cells after $10^{-7} \mathrm{M} I \alpha, 25(\mathrm{OH})_{2} \mathrm{D}_{3}$ or MART-I0 treatment for 2 days. Tubulin was used as the loading control. (B) Quantitative result of the Western blot showing E-cadherin and $\mathrm{N}$-cadherin expressions in FaDu cells after 2 days of $10^{-7} \mathrm{M} I \alpha, 25(\mathrm{OH}){ }_{2} \mathrm{D}_{3}$ or MART-I0 treatment. Each value is a mean \pm SD of three independent determinations $(* P<0.05)$.

Abbreviation: MART-10, 19-Nor-2 $\alpha$-(3-hydroxypropyl)- $1 \alpha, 25(\mathrm{OH})_{2} \mathrm{D}_{3}$.

A

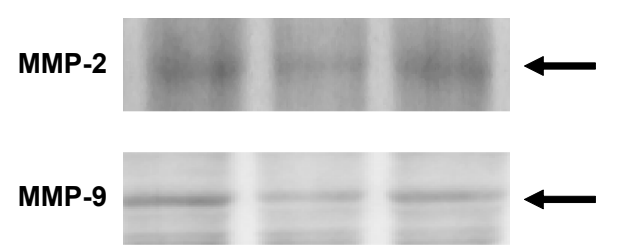

Tubulin
B

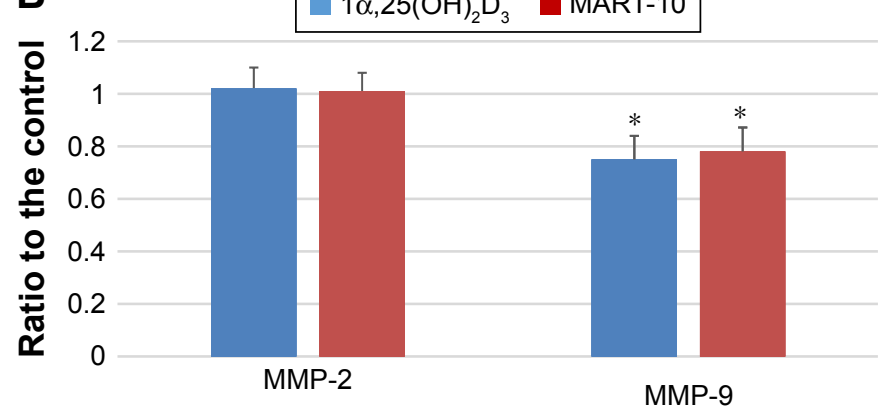

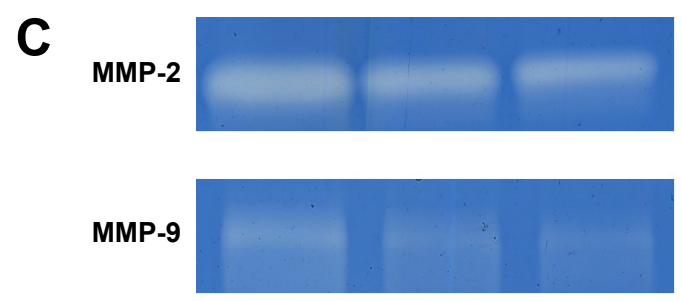

Figure 5 Effects of $\mathrm{I} \alpha, 25(\mathrm{OH})_{2} \mathrm{D}_{3}$ and MART-10 on intracellular expression and extracellular activity of MMP-2 and MMP-9 in FaDu cells.

Notes: (A) Western blot depicting the expressions of MMP-2 and MMP-9 in FaDu cells after 2 days of $10^{-7} \mathrm{M} I \alpha, 25(\mathrm{OH})_{2} \mathrm{D}_{3}$ or MART-I0 treatment. Tubulin was used as the loading control. (B) Quantitative analysis of MMP-2 and MMP-9 expressions in FaDu cells after treatment. Each value was a mean \pm SD of three independent determinations $(* P<0.05)$. (C) The extracellular MMP-2 and MMP-9 activities of FaDu cells were analyzed by zymography. After 2 days of treatment, conditioned media were collected for activity assay. The digested areas (white bands) corresponded to the activities of MMP-2 and MMP-9.

Abbreviation: MART-10, I9-Nor-2 $\alpha$-(3-hydroxypropyl)- $\mid \alpha, 25(\mathrm{OH})_{2} \mathrm{D}_{3}$. 
radiotherapies, ${ }^{27}$ which further worsens the prognosis. EMT process in cells is well orchestrated and could be regulated transcriptionally, translationally, or posttranslationally. ${ }^{23}$ Regarding transcriptional regulation, Snail, Slug, Zeb1/2, and Twist have been implicated in triggering EMT process. ${ }^{28}$ Our result revealed that Snail and Twist expressions in FaDu cells were inhibited by $10^{-7} \mathrm{M} 1 \alpha, 25(\mathrm{OH})_{2} \mathrm{D}_{3}$ and MART-10 (Figure 3), suggesting that both $1 \alpha, 25(\mathrm{OH})_{2} \mathrm{D}_{3}$ and MART-10 could repress EMT process in HNSCC cells, leading to the attenuation of migration and invasion, as shown in Figures 1 and 2.

Another hallmark of EMT is the "cadherin-switch", referring to the downregulation of E-cadherin and upregulation of $\mathrm{N}$-cadherin. ${ }^{13,14}$ Cadherin belongs to one kind of cell adhesion molecules, which plays a vital role in maintaining the structures of cells and tissues. ${ }^{29}$ Upregulation of E-cadherin is able to increase cell-cell adhesion. On the contrary, downregulation of E-cadherin could make cancer cells detach from the primary sites, leading to metastasis. Low E-cadherin expression has been linked with poor prognosis or advanced stage disease of cancers. ${ }^{30-32}$ Unlike E-cadherin, N-cadherin functions to decrease cell-cell adhesion, and thus aberrant expression of $\mathrm{N}$-cadherin has been reported to link with increased cancer invasiveness. ${ }^{33,34}$ The finding that both $1 \alpha, 25(\mathrm{OH})_{2} \mathrm{D}_{3}$ and MART-10 could upregulate E-cadherin expression while inhibiting $\mathrm{N}$-cadherin expression in $\mathrm{FaDu}$ cells further demonstrates that $1 \alpha, 25(\mathrm{OH})_{2} \mathrm{D}_{3}$ and MART-10 are able to repress EMT process in FaDu cells (Figure 4).

To move from one place to another, cancer cells need to digest the surrounding tissues. MMPs are collagenases functioning to digest the basement membrane. It has been reported that serum MMP-2 and MMP-9 levels are higher in laryngeal SCC patients, ${ }^{35}$ and serum vitamin D level has been found to be reversely associated with serum MMP-2 and MMP-9 levels. ${ }^{36}$ Our result shows that intracellular MMP-9 expression and extracellular MMP-9 activity of FaDu cells were inhibited by $1 \alpha, 25(\mathrm{OH})_{2} \mathrm{D}_{3}$ and MART-10 (Figure 5), leading to the less-invasive phenotype noted in Figure 1. Of note, MMP-2 expression and activity were not influenced by $1 \alpha, 25(\mathrm{OH})_{2} \mathrm{D}_{3}$ and MART-10.

\section{Conclusion}

Our result indicates that the newly synthesized $1 \alpha, 25(\mathrm{OH})_{2} \mathrm{D}_{3}$ analog, MART-10, is an effective drug to inhibit HNSCC cell metastasis to a greater extent than $1 \alpha, 25(\mathrm{OH})_{2} \mathrm{D}_{3}$. $1 \alpha, 25(\mathrm{OH})_{2} \mathrm{D}_{3}$ and MART-10 repressed Snail and Twist expressions and reversed cadherin switch in $\mathrm{FaDu}$ cells, indicating that both drugs attenuated EMT process in $\mathrm{FaDu}$ cells. In addition, intracellular MMP-9 expression and extracellular MMP-9 activity were inhibited by both drugs. Adding that MART-10 has been previously proved to be able to repress HNSCC cell growth, our current data strongly suggest that MART-10 should be deemed as a promising agent for HNSCC treatment. Further in vivo studies are warranted.

\section{Acknowledgments}

This work is supported by grants from Chang Gung Memorial Hospital (CMRPG2D0011, 2D0012, and 2D0013) to ShihWei Yang. The authors also thank Jun-Te Hsu, Li-Wei Chen, and Sheng-Fong Kuo for their help in revising this article.

\section{Disclosure}

The authors report no conflicts of interest in this work.

\section{References}

1. Muto M, Nakane M, Katada C, et al. Squamous cell carcinoma in situ at oropharyngeal and hypopharyngeal mucosal sites. Cancer. 2004; 101(6):1375-1381.

2. Azad AK, Bairati I, Samson E, et al. Validation of genetic sequence variants as prognostic factors in early-stage head and neck squamous cell cancer survival. Clin Cancer Res. 2012;18(1):196-206.

3. Chiang KC, Chen TC. The anti-cancer actions of vitamin D. Anticancer Agents Med Chem. 2013;13(1):126-139.

4. Chiang KC, Yeh CN, Chen MF, Chen TC. Hepatocellular carcinoma and vitamin D: a review. J Gastroenterol Hepatol. 2011;26(11):1597-1603.

5. Gedlicka C, Hager G, Weissenbock M, et al. 1,25(OH)2Vitamin D3 induces elevated expression of the cell cycle inhibitor $\mathrm{p} 18$ in a squamous cell carcinoma cell line of the head and neck. J Oral Pathol Med. 2006;35(8):472-478.

6. Hager G, Formanek M, Gedlicka C, Thurnher D, Knerer B, Kornfehl J. $1,25(\mathrm{OH}) 2$ vitamin D3 induces elevated expression of the cell cycleregulating genes P21 and P27 in squamous carcinoma cell lines of the head and neck. Acta Otolaryngol. 2001;121(1):103-109.

7. Prudencio J, Akutsu N, Benlimame N, et al. Action of low calcemic 1alpha,25-dihydroxyvitamin D3 analogue EB1089 in head and neck squamous cell carcinoma. J Natl Cancer Inst. 2001;93(10):745-753.

8. Ono K, Yoshida A, Saito N, et al. Efficient synthesis of 2-modified 1alpha,25-dihydroxy-19-norvitamin D3 with Julia olefination: high potency in induction of differentiation on HL-60 cells. J Org Chem. 2003; 68(19):7407-7415.

9. Hourai S, Fujishima T, Kittaka A, et al. Probing a water channel near the A-ring of receptor-bound 1 alpha,25-dihydroxyvitamin D3 with selected 2 alpha-substituted analogues. J Med Chem. 2006;49(17):5199-5205.

10. Suhara Y, Nihei KI, Kurihara M, et al. Efficient and versatile synthesis of novel 2alpha-substituted 1alpha,25-dihydroxyvitamin $\mathrm{D}(3)$ analogues and their docking to vitamin D receptors. J Org Chem. 2001; 66(26):8760-8771.

11. Yasuda K, Ikushiro S, Kamakura M, et al. Human cytochrome P450dependent differential metabolism among three 2alpha-substituted1alpha,25-dihydroxyvitamin D(3) analogs. J Steroid Biochem Mol Biol. 2013;133:84-92.

12. Chiang KC, Yeh CN, Chen HY, et al. 19-Nor-2alpha-(3-hydroxypropyl)1alpha,25-dihydroxyvitamin D3 (MART-10) is a potent cell growth regulator with enhanced chemotherapeutic potency in liver cancer cells. Steroids. 2011;76(13):1513-1519. 
13. Chiang $\mathrm{KC}$, Yeh $\mathrm{CN}$, Chen SC, et al. MART-10, a new generation of vitamin $\mathrm{D}$ analog, is more potent than 1alpha,25-dihydroxyvitamin $\mathrm{D}(3)$ in inhibiting cell proliferation and inducing apoptosis in ER+ MCF-7 breast cancer cells. Evid Based Complement Alternat Med. 2012; 2012:310872.

14. Kittaka A, Yoshida A, Chiang KC, et al. Potent 19-norvitamin D analogs for prostate and liver cancer therapy. Future Med Chem. 2012;4(16): 2049-2065.

15. Chiang KC, Yeh CN, Hsu JT, et al. Evaluation of the potential therapeutic role of a new generation of vitamin D analog, MART-10, in human pancreatic cancer cells in vitro and in vivo. Cell Cycle. 2013;12(8): 1316-1325.

16. Chiang KC, Chen SC, Yeh CN, et al. MART-10, a less calcemic vitamin D analog, is more potent than 1alpha,25-dihydroxyvitamin D3 in inhibiting the metastatic potential of MCF-7 breast cancer cells in vitro. J Steroid Biochem Mol Biol. 2014;139:54-60.

17. Chiang KC, Kuo SF, Chen CH, et al. MART-10, the vitamin D analog, is a potent drug to inhibit anaplastic thyroid cancer cell metastatic potential. Cancer Lett. 2015;369(1):76-85.

18. Chiang KC, Yeh CN, Hsu JT, et al. The vitamin D analog, MART-10, represses metastasis potential via downregulation of epithelialmesenchymal transition in pancreatic cancer cells. Cancer Lett. 2014; 354(2):235-244.

19. Chiang KC, Yeh CN, Hsu JT, et al. MART-10, a novel vitamin D analog, inhibits head and neck squamous carcinoma cells growth through cell cycle arrest at G0/G1 with upregulation of p21 and p27 and downregulation of telomerase. J Steroid Biochem Mol Biol. 2013;138:427-434.

20. Flanagan JN, Zheng S, Chiang KC, et al. Evaluation of 19-nor-2alpha(3-hydroxypropyl)-1alpha,25-dihydroxyvitamin D3 as a therapeutic agent for androgen-dependent prostate cancer. Anticancer Res. 2009; 29(9):3547-3553.

21. Iglesias-Gato D, Zheng S, Flanagan JN, et al. Substitution at carbon 2 of 19-nor-1alpha,25-dihydroxyvitamin D3 with 3-hydroxypropyl group generates an analogue with enhanced chemotherapeutic potency in PC-3 prostate cancer cells. J Steroid Biochem Mol Biol. 2011; 127(3-5):269-275.

22. Yilmaz M, Christofori G. Mechanisms of motility in metastasizing cells. Mol Cancer Res. 2010;8(5):629-642.

23. Lamouille S, Xu J, Derynck R. Molecular mechanisms of epithelial-mesenchymal transition. Nat Rev Mol Cell Biol. 2014;15(3): $178-196$.
24. Thiery JP, Acloque H, Huang RY, Nieto MA. Epithelial-mesenchymal transitions in development and disease. Cell. 2009;139(5):871-890.

25. Hollier BG, Evans K, Mani SA. The epithelial-to-mesenchymal transition and cancer stem cells: a coalition against cancer therapies. J Mammary Gland Biol Neoplasia. 2009;14(1):29-43.

26. Arumugam T, Ramachandran V, Fournier KF, et al. Epithelial to mesenchymal transition contributes to drug resistance in pancreatic cancer. Cancer Res. 2009;69(14):5820-5828.

27. Kurrey NK, Jalgaonkar SP, Joglekar AV, et al. Snail and slug mediate radioresistance and chemoresistance by antagonizing p53-mediated apoptosis and acquiring a stem-like phenotype in ovarian cancer cells. Stem Cells. 2009;27(9):2059-2068.

28. Peinado H, Olmeda D, Cano A. Snail, Zeb and bHLH factors in tumour progression: an alliance against the epithelial phenotype? Nat Rev Cancer. 2007;7(6):415-428.

29. Kim JB, Islam S, Kim YJ, et al. N-cadherin extracellular repeat 4 mediates epithelial to mesenchymal transition and increased motility. $J$ Cell Biol. 2000;151(6):1193-1206.

30. Birchmeier W, Hulsken J, Behrens J. Adherens junction proteins in tumour progression. Cancer Surv. 1995;24:129-140.

31. TsanouE, Peschos D, Batistatou A, Charalabopoulos A, Charalabopoulos K. The E-cadherin adhesion molecule and colorectal cancer. A global literature approach. Anticancer Res. 2008;28(6A):3815-3826.

32. Joo YE, Rew JS, Park CS, Kim SJ. Expression of E-cadherin, alpha- and beta-catenins in patients with pancreatic adenocarcinoma. Pancreatology. 2002;2(2):129-137.

33. Derycke LD, Bracke ME. N-cadherin in the spotlight of cell-cell adhesion, differentiation, embryogenesis, invasion and signalling. Int J Dev Biol. 2004;48(5-6):463-476.

34. Nakajima S, Doi R, Toyoda E, et al. N-cadherin expression and epithelial-mesenchymal transition in pancreatic carcinoma. Clin Cancer Res. 2004;10(12 Pt 1):4125-4133.

35. Lotfi A, Mohammadi G, Saniee L, Mousaviagdas M, Chavoshi H, Tavassoli A. Serum level of matrix metalloproteinase-2 and -9 in patients with laryngeal squamous cell carcinoma and clinical significance. Asian Pac J Cancer Prev. 2015;16(15):6749-6751.

36. Timms PM, Mannan N, Hitman GA, et al. Circulating MMP9, vitamin $\mathrm{D}$ and variation in the TIMP-1 response with VDR genotype: mechanisms for inflammatory damage in chronic disorders? QJM. 2002; 95(12):787-796.
Drug Design, Development and Therapy

\section{Publish your work in this journal}

Drug Design, Development and Therapy is an international, peerreviewed open-access journal that spans the spectrum of drug design and development through to clinical applications. Clinical outcomes, patient safety, and programs for the development and effective, safe, and sustained use of medicines are a feature of the journal, which

\section{Dovepress}

has also been accepted for indexing on PubMed Central. The manuscript management system is completely online and includes a very quick and fair peer-review system, which is all easy to use. Visit http://www.dovepress.com/testimonials.php to read real quotes from published authors. 